\title{
Pengaruh Bimbingan Keagamaan Terhadap Perubahan Perilaku Anak
}

\author{
Anelvi Novitasari ${ }^{1}$ Nurul Hakiki $^{2}$, Zulkipli Lessy ${ }^{3}$ \\ ${ }^{1}$ Universitas Islam Negeri Sunan Kalijaga \\ ${ }^{2}$ Universitas Islam Negeri Sunan Kalijaga \\ 3 Universitas Islam Negeri Sunan Kalijaga
}

\section{Article Info \\ Article history: \\ Received Jun $12^{\text {th }}, 2021$ \\ Revised Aug 20 ${ }^{\text {th }}, 2021$ \\ Accepted oct $30^{\text {th }}, 2021$}

\section{Keyword:}

Bimbingan Keagamaan Islam, Perilaku Anak, Norma Agama

\begin{abstract}
Perilaku menyimpang atau perilaku yang tidak sesuai dengan norma-norma agama dan Al-Qur'an di kalangan anak-anak Panti Asuhan Fajar Iman Azzahra Kecamatan Tampan Kota Pekanbaru menjadi isu utama penelitian ini, yang bertujuan untuk menguji bagaimana pengaruh bimbingan keagamaan Islam terhadap perubahan perilaku anak. Metode yang digunakan dalam penelitian ini adalah deskriptif kuantitatif dengan menggunakan analisis regresi linier sederhana program SPSS 17.0 For Windows. Teknik pengambilan sampel adalah dengan cara purposive sampling, yaitu teknik penentuan mengambil subjek bukan berdasarkan atas strata, random, atau daerah tetapi didasarkan atas adanya tujuan tertentu dengan jumlah sampling 45 anak. Hasil penelitian ini nilai korelasi variabel X dan Y sebesar 0.014. Berdasarkan analisa data pada Tabel Model Summary bahwa nilai $\mathrm{R}$ square 0,82 atau $0,28 \%$ berada pada rentang interval 0,00-0,199 dalam kategori sangat rendah. Namun demikian keduanya masih tetap memiliki hubungan dan terdapat adanya pengaruh variabel luar. Jadi berdasarkan hasil penelitian ini, terdapat adanya pengaruh bimbingan keagamaan Islam terhadap perubahan perilaku anak.
\end{abstract}

Corresponding Author:
Zulkipli Lessy
Universitas Islam Negeri Sunan Kalijaga
Email: zulkipli.lessy@uin-suka.ac.id

\section{Pendahuluan}

Orang tua pasti menyadari bahwa seorang anak merupakan amanat dari Allah yang harus dijaga, dibina, dan dididik dengan sebaik-baiknya. Sejak seorang anak lahir, ia akan diperkenalkan dengan aturanaturan, norma-norma dan nilai-nilai budaya yang berlaku, yang diberikan oleh orang tua dalam lingkungan keluarga. Dengan demikian, anak perlu mendapatkan pembinaan agar ia dapat tumbuh dan berkembang sesuai norma-norma yang berlaku dalam masyarakat (Ihromi, 1999). Perilaku baik dan buruknya seorang anak terbentuk dari lingkungan sekitarnya, terutama dalam lingkungan tempat tinggalnya. Maka dari itu, setiap orang tua mempunyai tanggung jawab yang besar dalam mendidik anak-anaknya agar menjadi pribadi yang baik, bermanfaat dan berperilaku yang sesuai norma-norma yang berlaku dalam lingkungan keluarga maupun dalam lingkungan bermasyarakat. Untuk mencapai tujuan tersebut seorang anak membutuhkan bimbingan termasuk bimbingan keagamaan, dimana bimbingan kegamaan ini diharapkan dapat membentuk karakter dan perilaku anak kearah yang lebih baik dan dapat berguna bagi lingkungan dan agama (Nasution, 1995). 
Seperti yang kita ketahui bimbingan ialah merupakan sebuah arahan yang dilakukan oleh seorang dewasa untuk menuntun orang lain/individu yang kearah yang lebih baik di kehidupannya sekarang dan di kehidupannya yang akan datang (Nasution, 1995). Sedangkan keagamaan adalah ajaran dan dogma yang mengatur tentang hubungan antara manusia dan Sang Pencipta, dimana hubungan tersebut terjadi dalam batin seseorang yang tercermin dalam ibadah yang dilakukan dan juga terlihat dari sikap keseharian yang ia tunjukkan.

Matry dalam Nurhayanti (2016) mengartikan bahwa bimbingan merupakan suatu bantuan yang diberikan secara berkesinambungan kepada seorang individu, dengan tujuan agar individu tersebut dapat memahami dirinya dengan baik, sehingga individu itu juga mampu membawa dirinya kearah perilaku yang baik, sesuai dengan tuntutan keadaan di lingkungannya, baik sekolah, keluarga, dan masyarakat pada umumnya, dimana pada dasarnya bimbingan ini dilakukan oleh orang tua dengan berbagai cara, baik dengan tingkah laku yang dicontohkan sehari-hari maupun dengan perintah langsung (Nurhayanti, 2016). Segala kegiatan yang dilakukan oleh seseorang dalam rangka memberi bantuan kepada seseorang atau orang yang mengalami kesulitan-kesulitan dalam hidupnya agar mampu mengatasinya secara mandiri karena timbul kesadaran atau penyerahan diri kepada kekuasaan Allah SWT.Karena itu, bimbingan keagamaan menjadi penting bagi setiap orang terutama generasi penerus bangsa, khususnya anak-anak yang memiliki perilaku buruk agar dapat merubah perilakunya dengan baik. Meskipun memiliki latar belakang negatif, sebagai manusia yang memiliki akal untuk berfikir, anak-anak ini layak untuk mendapatkan bimbingan agama, dalam hal ini Islam. Manusia memiliki derajat yang lebih tinggi dibandingkan dengan makhluk-makhluk yang lainnya, dan perbedaannya terletak pada akal.

Berdasarkan pemaparan diatas kami tertarik untuk meneliti mengenai seberapa besar pengaruh bimbingan keagamaan, dalam hal ini Islam, apabila diberikan kepada anak-anak, dan apakah ada perubahan perilaku pada diri mereka. Adapun investigasi ini terlaksana di Panti Asuhan Iman Azzahra Kota Pekanbaru sebagai lokus penelitian.Berdasarkan temuan awal penelitian terkait situasi di Panti Asuhan Fajar Iman Azzahra bahwa masih banyak anak di panti asuhan tersebut yang merasa tidak pencaya diri serta minder. Salah satu indikator ketidakpercayaan diri adalah mereka menganggap bahwa Allah tidak adil dalam memperlakukan mereka dengan memberikan kepada mereka kehidupan yang serba kekurangan dan keterbatasan. Selanjutnya, yang menarik perhatian kami adalah anak-anak binaan panti asuhan berasal dari latar belakang yang berbeda, dan kondisi ini tentu mencerminkan mereka memiliki tingkah laku yang berbeda, diantara mereka ada yang sebelumnya mendapatkan bimbingan keagamaan dari keluarganya, dan ada juga yang sama sekali belum mendapatkan bimbingan keagamaan dari keluarganya. Karena itu, ketika mereka berada atau tinggal di panti asuhan, mereka mendapatkan bimbingan, seperti bimbingan keagamaan Islam agar mereka berperilaku sesuai dengan nilai-nilai dan norma-norma susila yang baik atau sesuai dengan AlQur'an dan Hadits.

Adanya kasus-kasus mencuri, tidak mengikuti shalat berjamaah, tidak mengaji, dan melanggar peraturan panti asuhan lainnya. Dengan demikian perkembangan kepribadian anak sangat tergantung pada baik atau tidaknya proses bimbingan yang ditempuh.Perkembangan mentalitas dan pertumbuhan masingmasing anak tidak merata karena dipengaruhi oleh banyak faktor, salah satu adalah mentalitas bawaan. Tetapi, banyak anak yang berada didalam lingkungan panti asuhan mempunyai latar belakang yang sama; karenanya mereka memerlukan perhatian yang khusus dari para pengelola atau orang tua asuh.

\section{Metode}

Penelitian ini peneliti menggunakan metode penelitian kuantitatif, dimana penelitian ini melihat seberapa besar pengaruh variabel bebas (independent) terhadap variabel terkait (dependent) (Neuman, 2017). Pengumpulan data menggunakan instrumen penelitian, dan analisis data bersifat kuantitatif/statistik dengan tujuan untuk menguji hipotesis yang telah ditetapkan (Healey, 2010). Dan, pendekatan yang kami gunakan dalam penelitian ini adalah pendekatan kuantitatif asosiatif, yang bertujuan untuk mengetahui tingkat hubungan antara dua variabel atau lebih, dan melihat besar pengaruh variabel $(x)$ terhadap variabel $(y)$ (Emanuel J Mason; William J Bramble, 2007). Penelitian ini dilakukan di Panti Asuhan Fajar Iman Azzahra yang berlokasi di Panam Jalan Garuda Sakti, Kecamatan Tampan, Kota Pekanbaru, Provinsi Riau. Populasi dan sampel dalam penelitian ini ialah seluruh anak Panti Asuhan Fajar Iman Azzahra yang berjumlah 45 anak, dan kemudian kami mengambil sampel sebesar 73,33\% yaitu 33 anak. Teknik pengambilan sampel yaitu dengan purposive sampling (Riduwan, 2013).

Pengumpulan data dilakukan dengan skala likert, skala ini berinteraksi 1-5 yang mempunyai gradasi dari positif sampai negative. Uji Validitas yang dilakukan dalam penelitian ini ialah dengan cara skor-skor pada setiap butir soal, kemudian diuji dengan rumus validitas dan dibandingkan dengan ( $\mathrm{r}_{\text {tabel }}$ ), apabila nilai ( $\mathrm{r}$ hitung $)$, lebih besar dari nilai ( $\left.\mathrm{r}_{\text {tabel }}\right)$, maka dinyatakan valid. 
Dalam penelitian ini peneliti menggunakan program SPSS 17.0 For Windows agar mempermudah peneliti dalam proses penentuan hasil. Adapun metode analisis data yang digunakan ialah dengan menggunakan koefisien korelasi dengan menggunakan cara analisis regresi linier sederhana, yaitu persamaan regresi linear sederhana dan analisis hipotesis (Hinkle, Wiersma, \& Jurs, 1990). Adapun bentuk persamaan regresi sederhana sebagai berikut:

$(Y=a+B x)$

Dimana :

Y : Variabel tidak bebas atau variabel terikat

$\mathrm{X}$ : Variabel bebas

a : $\quad$ Nilai intercepti konstan atau harga $Y$ bila $X=0$

B : Koefisien regresi, yaitu angka peningkatan atau penurunan variabel dependen yang berdasarkan pada variabel indenpenden (Sugiyono, 2013).

Pengujian hipotesis dilakukan dengan uji normalitas menggunaan teknik analisis Colmegorov Smirnov test dengan program SPSS versi 17 pada probabilitas $\mathrm{a}=0,05$ berikut hipotesis yang diajukan untuk uji normalitas (Riduwan, 2013):

Ha: Bimbingan keagamaan Islam berpengaruh terhadap perubahan perilaku anak di Panti Asuhan Fajar Iman Azzahra.

Ho: Bimbingan keagamaan Islam tidak berpengaruh terhadap perubahan perilaku anak di Panti Asuhan Fajar Iman Azzahra.

Jika nilai probabilitas 0,05 lebih kecil atau sama dengan nilai Sigatau $[0,05 \leq \mathrm{Sig}]=$ maka Ho diterima Ha ditolak, artinya tidak ada pengaruh bimbingan keagamaan Islam terhadap perubahan perilaku anak di Panti Asuhan Fazar Iman Azzahra Kecamatan Tampan Kota Pekanbaru. Jika nilai probabilitas 0,05 lebih besar atau sama dengan nilai $\mathrm{Sig}$ atau $[0,05 \geq \mathrm{Sig}]=$ Maka Ha diterima dan Ho ditolak, artinya tidak ada pengaruh bimbingan keagamaan Islam terhadap perubahan perilaku anak di Panti Asuhan Fajar Iman Azzahra Kecamatan Tampan Kota Pekanbaru.

\section{Hasil dan Pembahasan}

Untuk mengetahui dan membuktikan adanya pengaruh dari bimbingan keagamaan islam terhadap perubahan perilaku anak di Panti Asuhan Fajar Iman Azzahra (variabel independen dan variabel dependen), peneliti menggunakan rumus regresi linier sederhana yang diolah menggunakan data SPSS 17.0. dan kemudian setelah diperoleh hubungan antara kedua variabel tersebut, peneliti akan menginterpretasikan nilai tersebut dalam tabel untuk melihat seberapa besar pengaruhnya. dan hasil yang diperoleh adalah sebagai berikut:

Tabel.1

Korelasi Respon Bimbingan Keagamaan Islam Terhadap Perubahan Perilaku

\begin{tabular}{llcc}
\hline & & $\begin{array}{c}\text { Perubahan } \\
\text { Perilaku }\end{array}$ & $\begin{array}{c}\text { Bimbingan } \\
\text { Keagamaan } \\
\text { Islam }\end{array}$ \\
\hline Pearson Correlation & $\begin{array}{l}\text { Perubahan Perilaku } \\
\text { Bimbingan Keagamaan }\end{array}$ & 1.000 & .382 \\
Sig. (1-tailed) & Islam & .382 & 1.000 \\
& Perubahan Perilaku &. & .014 \\
N & Bimbingan Keagamaan & .014 &. \\
& Islam & 33 & 33 \\
& Perubahan Perilaku & 33 & 33 \\
\hline & Bimbingan Keagamaan & 3 & \\
\hline
\end{tabular}

(Sumber : Hasil Data Olahan SPSS 17.0) 
Jadi hasil Correlations variabel X dan Y. Nilai yang diperoleh sebesar 0.014 berarti terdapat hubungan yang signifikan antara variabel bimbingan keagamaan Islam dengan variabel perubahan perilaku. Dari tabel V.43 dapat diketahui bahwa apabila variabel independen bertambah 1,000 maka variabel independen juga bertambah sebesar 0,382 . Untuk membuktikan hipotesis "terdapat hubungan yang signifikan antara variabel $\mathrm{X}$ dan Y" dapat dilihat dari tabel V.43 bahwa tingkat signifikan 0,014 lebih kecil dibandingkan $=0,05$. Dari hasil pengamatan langsung, penyebaran angket dan kuesioner yang dilakukan dan kemudian melihat pedoman interpretasi koefisien korelasi pada tabel 1 diperoleh hail bahwa Bimbingan Keagamaan Islam berpengaruh terhadap perubahan perilaku anak di Panti Asuhan Fajar Iman Azzahra, namun tingkat pengaruh bimbingan keagamaan islam tersebut sangat rendah.

Setelah hasil diatas diperoleh kemudian peneliti melakukan uji hipotesis dengan rumus :

$\mathrm{Ha}: \mathrm{r}_{\mathrm{yx}} \neq 0$

Ho : $r_{\mathrm{yx}}=0$

Hipotesis bentuk kalimat

$\mathrm{Ha}$ : Bimbingan keagamaan Islam berpengaruh signifikan terhadap perubahan perilaku anak panti asuhan Fajar Iman Azzahra.

Ho : Bimbingan Keagamaan Islam tidak berpengaruh signifikan terhadap perubahan perilaku anak panti asuhan Fajar Iman Azzahra.

Untuk menguji hipotesis digunakan uji sig. Pengambilan keputusan dapat dilihat dengan membandingkan nilai Sig 0.05. Atau nilai Sig $0.05 \geq$ Sig maka Ho ditolak dan Ha diterima, artinya signifikan. Tetapi jika nilai Sig $0.05 \leq$ Sig tabel maka Ho diterima dan Ha ditolak, artinya tidak signifikan dan diperoleh hasil sebagai berikut :

Tabel.2

Uji Hipotesis

\begin{tabular}{|c|c|c|c|c|c|}
\hline \multirow{2}{*}{ Model } & \multicolumn{2}{|c|}{$\begin{array}{l}\text { Unstandardized } \\
\text { Coefficients }\end{array}$} & \multirow{2}{*}{$\begin{array}{c}\text { Standardized } \\
\text { Coefficients } \\
\text { Beta } \\
\end{array}$} & \multirow{2}{*}{$\mathbf{t}$} & \multirow{2}{*}{ Sig. } \\
\hline & B & Std. Error & & & \\
\hline (Constant) & 39.172 & 8.133 & & 4.816 & .000 \\
\hline $\begin{array}{l}\text { Bimbingan } \\
\text { Keagamaan } \\
\text { Islam }\end{array}$ & .337 & .146 & .382 & 2.303 & .028 \\
\hline
\end{tabular}

Tabel 2 menunjukan diperoleh variabel bimbingan keagamaan Islam dan perubahan perilaku dengan nilai Sig. Sebesar 0.028, kemudian dibandingkan dengan probabilitas Sig 0.05, ternyata nilai probabilitas Sig 0.05 lebih besar dari nilai Sig atau $(0.05 \geq 0.028)$, maka Ho ditolak dan Ha diterima artinya signifikan. Dengan demikian terdapat adanya pengaruh antara bimbingan keagamaan Islam terhadap perubahan perilaku anak Panti Asuhan Fajar Iman Azzahra.

\section{Kesimpulan}

Hasil analisis menunjukkan adanya perubahan perilaku terhadap anak di Panti Asuhan Fajar Iman Azzahra Pekanbaru setelah diberikan Bimbingan Keagamaan Islam, dilihat dari hasil korelasi antara Bimbingan Keagamaan Islam terhadap perubahan perilaku anak di Panti Asuhan Fazar Iman Azzahra Pekanbaru dengan koefisien 0,382 yang berada pada interval 0,00-0,199 dengan tingkat hubungan sangat rendah, tetapi keduanya terdapat hubungan. Jadi ada variable lain diluar penelitian ini yang dapat melihat pengaruh Bimbingan Keagamaan Islam. Dan nilai koefisien regresi pada penelitian ini adalah $\mathrm{Y}=$ $39.172+0,337 \mathrm{X}$ dengan tingkat signifikan 0,028 lebih kecil dibandingkan nilai probabilitas yaitu 0,005 yang artinya hipotesis alternatif diterima.

\section{References}

Andria, T. (2016). Peran bimbingan keagamaan dalam penanggulangan kenakalan remaja. Jurnal Bimas Islam 9(1), 151-206. https://jurnalbimasislam.kemenag.go.id/jbi/article/view/138

Arifin, M. (1994).Pedoman pelaksanaan bimbingan dan penyuluhan agama. Jakarta: Golden Terayon.

Bluman, A.G. (2017). Elementary statistics: A step by step approach. Boston, MA: McGraw-Hill. 
Hasanah, E.U. (2019). Bimbingan keagamaan terhadap kedisiplinan shalat anak di Panti Asuhan Al-

Muqaramah Assa Sukabumi Bandar Lampung. Diploma thesis, Program Studi Bimbingan Konseling Islam Fakultas Dakwah dan Komunikasi Universitas Islam Negeri Raden Intan Bandar Lampung.

Healey, J.F. (2010). The essentials of statistics: A tool for social research. Belmont, CA: Wadsworth.

Hinkle, D.E., Wiersma, W., \& Jurs, S. G. (1990). Applied Statistics for the Behavioral Sciences. Belmont, CA: Houghton, Mifflin.

Ihromi, T.O. (1999). Bunga rampai sosiologi keluarga. Jakarta: Yayasan Obor Indonesia.

Iskandar. (2009). Metode penelitian kuantitatif dan kualitatif. Jakarta: GP Press.

Mason, E.J., \& Bramble, W.J. (2007). Research in education and the behavioral sciences : concepts and methods. IA: Brown and Benchmark.

Nasution, S. (1995). Didaktik asas-asas mengajar. Jakarta: Bina Aksara.

Neuman, W.L. (2017). Social research methods: Qualitative and quantitative approaches. Boston, MA: Allyn and Bacon.

Nurhayanti, S. (2016). Pengaruh bimbingan keagamaan terhadap disiplin shalat berjamaah pada remaja: Penelitian di yayasan Bening Nurani Tanjungsari Sumedang.Diploma thesis, UIN Raden Intan Bandar Lampung.

Pagano, R.R. (2001). Understanding statistics in the behavioral sciences. Belmont, CA: Wadsworth.

Pitoyo, A. (2011). Pengaruh bimbingan keagamaan dalam keluarga terhadap pengamalan ibadah anak di rw 06 Kelurahan Susukan Kecamatan Ungaran Timur Kabupaten Semarang.Unpublished paper, Program Studi Pendidikan Agama Islam Sekolah Tinggi Agama Islam Negeri Salatiga.

Riduwan. (2013). Skala pengukuran variabel-variabel penelitian. Bandung:Alfabeta.

Riduwan, Rusyana, A., \& Enas. (2013). Cara mudah belajar SPSS 17.0 dan aplikasi statistik penelitian. Bandung: Alfabeta.

Sugiyono. (2013). Metode penelitian kuantitatif, kualitatif, dan $R \& D$. Bandung: Alfabeta.

Sundari, M. (2021). Bimbingan keagamaan bagi anak jalanan di Rumah Singgah Al-Ma'un Kota Bengkulu. Diploma thesis, Program Studi Bimbingan Konseling Islam Fakultas Ushuluddin Adab dan Dakwah Institut Agama Islam Negeri Bengkulu. 